\title{
Digital health and financial good-governance: a mixed methods study of patient revenue capture in Malawi
}

\author{
Paul Kawale ${ }^{1}$, Liz Grant ${ }^{2}$, Claudia Pagliari ${ }^{2}$ \\ 1 Usher Institute, University of Edinburgh, Edinburgh, UK, \& African Institute for Development Policy, Lilongwe, Malawi, 2 Usher Institute, University of \\ Edinburgh, Edinburgh, UK \\ Keywords: financial management, developing countries, health systems strengthening, sdg16, good-governance, global health, administrative \\ information systems, health information systems, ehealth, digital health \\ https://doi.org/10.29392/001c.12258
}

\section{Journal of Global Health Reports}

Vol. 4, 2020

\section{Background}

Digital Health Information Systems (HIS) have potential to improve the finances of healthcare organisations in lower income countries through better tracking of patients and procedures, more timely billing, greater professional accountability and more informed decisions. However, little is known about how HIS influence these processes in such settings or how contextual and social factors mediate their implementation and impacts.

\section{Objectives}

This study investigated whether, and through what mechanisms, the implementation of a modular HIS influenced revenue capture from patient billing in a large referral hospital in Malawi, drawing on the perspectives of complex sociotechnical systems, health system strengthening and ICT for good-governance.

\section{Methods}

Retrospective mixed-methods case study involving documentary analysis of management reports, interviews with informed respondents and descriptive analysis of revenue data over an 8-year period. Key implementation stages were mapped against changes in patient revenue and triangulated with interview data to obtain a rich picture of the project over time.

\section{Results}

Trends in measured revenue were obfuscated by fluctuations in data recording procedures, government reimbursement for patient services, patient traffic (due to public health interventions) and inflationary instability. Interviewees reported that the system had improved hospital finances through introducing greater transparency and accountability, thus preventing illicit practices such as informal payments. However, triangulating qualitative and quantitative data revealed that introducing the HIS had little effect on revenue (or possibly the reverse) until independent Ward Clerks were introduced to operate the systems' billing and payment functions, thus reducing opportunities for entrenched practices to be replicated digitally.

\section{Conclusions}

Although it was not possible to draw firm conclusions about the effect of the HIS on billing and finance, qualitative findings from our study, coupled with data triangulation, align with other research indicating that HIS can help to improve efficiency and accountability in healthcare organisations, but that technology alone is unlikely to suffice. Further research is needed to understand the role of HIS as enablers of financial good-governance in low income country settings, to more robustly evaluate their impacts on work practices, efficiency and sustainability, and to understand the complex contextual and socio-cultural influences mediating these effects.

Digital health information systems (HIS) are a core feature of modern healthcare organisations, enabling clinical and administrative data to be captured and mobilised to support the delivery of patient care, operational and busi- 
ness processes, public health activities and research. ${ }^{1}$ HIS have been characterised as essential technologies for health systems strengthening. ${ }^{2}$

Strong health systems also rely on effective organisational governance 3,4 and HIS offer an important route towards achieving this, ${ }^{5}$ not least through aiding the management of finances. 6,7 However, while there are robust arguments for investing in HIS to improve the efficiency, quality and safety of care, ${ }^{8-10}$ relatively little is known about their effects on financial management in healthcare organisations.

In high-income countries such as the USA, computerbased analytical techniques have been used to identify fraudulent financial behaviour in health practices, ${ }^{11}$ especially related to insurance claims. ${ }^{12}$ Data mining has been used to reveal fraudulent behaviour involving collusion between health practitioners and pharmacies in Iran 13 and was also shown to detect $77.4 \%$ of prescription fraud among medical practices in Turkey. ${ }^{14}$ A UK governmentfunded practice paper addressing corruption in the health sector ${ }^{15}$ also pointed to the importance of ICT for reducing fraudulent billing for services through better accounting and transparency.

In lower income country health systems, the need to optimise efficiency is particularly acute, given the limited human and economic resources and the high burden of disease, 16 and information technologies are gradually being introduced as a means of addressing these challenges. ${ }^{17}$ Health systems in these settings are also often hindered by ingrained inefficiencies, corruption, social norms that discourage optimum work practices, and ineffective oversight, 18 which compromise their ability to provide safe and equitable patient care. Most of the major global health and development agencies have emphasised the need to address these problems and the new UN Sustainable Development Goals include an explicit commitment to strengthen institutional governance (Goal 16). 19 The concept of "goodgovernance", arose in the context of global development and emphasises ethical issues around the transparency, accountability and legality of organisational processes to ensure the efficient and equitable use of resources, alongside stakeholder participation. 20

The role of digital approaches in facilitating 'good governance' in low and middle income country (LMIC) health systems has recently been described, including innovative uses of mobile apps and social media for reporting corruption. 20 However, facility-based information systems can also help by improving the recording, sharing and use of data on care processes and services, thereby increasing transparency and accountability. One set of activities where this may be particularly valuable is patient billing and fee recovery, which can be vulnerable to error and manipulation, contributing to the significant 'leakage' of healthcare resources that occurs in low income countries each year. ${ }^{21}$ However, there has been little research on how digital health influences these processes in practice, or their effectiveness in doing so. The current study aims to help fill this knowledge gap.

Although evidence demonstrating the impacts of HIS in developing countries is needed, 22,23 reliably evaluating these impacts can be challenging, as their success may be influenced as much by aspects of the implementation process and the surrounding context, as by the technical capabilities of the innovation. For this reason, approaching information systems as sociotechnical interventions, in which software, users and organisations interact and influence one another over time, can be useful as an adjunct to other methods such as cost-effectiveness trials, which may be hard to do in these complex settings. ${ }^{23-25}$

Our study profiles the implementation and effects of a modular HIS in one large referral hospital in Malawi over its life course, from conception to integration, over a period of several years. Managers and staff had identified a lack of accurate and timely data as a major problem for the organisation, leading to ineffective documentation of services delivered, inadequate patient records, wasteful duplication of activities, and inconsistent or inaccurate billing. A decision had therefore been taken to procure and implement an HIS with a view to improving the monitoring of financial transactions and data, and supporting effective accounting, strategic decision-making and prioritisation. The analysis reported here focuses on understanding the influence of the HIS on hospital revenue capture from patient billing, with reference to sociotechnical and contextual factors.

\section{METHODS}

\section{SETTING}

The study took place at a 300-bed private non-profit faithbased facility on the border of Dedza and Lilongwe districts, Malawi. The hospital has medical, surgical, paediatrics, laboratory, X-ray, ophthalmic, maternity, outpatient, and primary health care departments. Pharmacy, administration, human resources, finance, and information technology (IT) sections support these departments. It services a rural catchment population of approximately 65,000 people and also provides referral care to a population of approximately 550,000 individuals. Nine rural health centres provide primary health care, including antenatal and delivery care, for the population that is not directly served by the hospital, and refer patients to the hospital for specialist care.

\section{INTERVENTION}

A modular HIS (AfyaPro, NPK technologies, Dar Es Salam, Tanzania) was selected in 2009 as a means of enabling data collection and sharing for patient care, hospital management, revenue collection and public health reporting. Implementation was informed by the WHO change management guide for health management information systems 26 and the Roundtable approach to stakeholder involvement. 27 The system itself was developed in Tanzania with the support of a Dutch non-profit agency specialising in ICT for Development. Figure 1 shows the user interface.

\section{DESIGN}

A retrospective, longitudinal, mixed methods case study design 28 was used, in which all data, including first-person accounts, were collected after the implementation of the HIS. Qualitative and quantitative data were analysed in parallel and converged, in order to obtain a holistic account of the implementation program over its life course and aid in- 
Table 1. Interview respondents.

\begin{tabular}{lccc}
\hline Respondent & Department & Gender & Role \\
1 & Clinical & Male & Management \\
2 & Clinical & Male & Management \\
3 & Pharmacy & Male & Head of Department \\
4 & Nursing & Female & Management \\
5 & Finance & Female & Management \\
6 & IT & Male & Technician \\
7 & IT & Male & Technician \\
8 & Reproductive and Child Health & Male & Clinician \\
9 & Paediatrics & Male & Middle-Management \\
11 & Reproductive and Child Health & Male & Middle-Management \\
12 & Paediatrics & Male & Data Clerk \\
13 & IT & Male & Head of Department \\
\hline
\end{tabular}

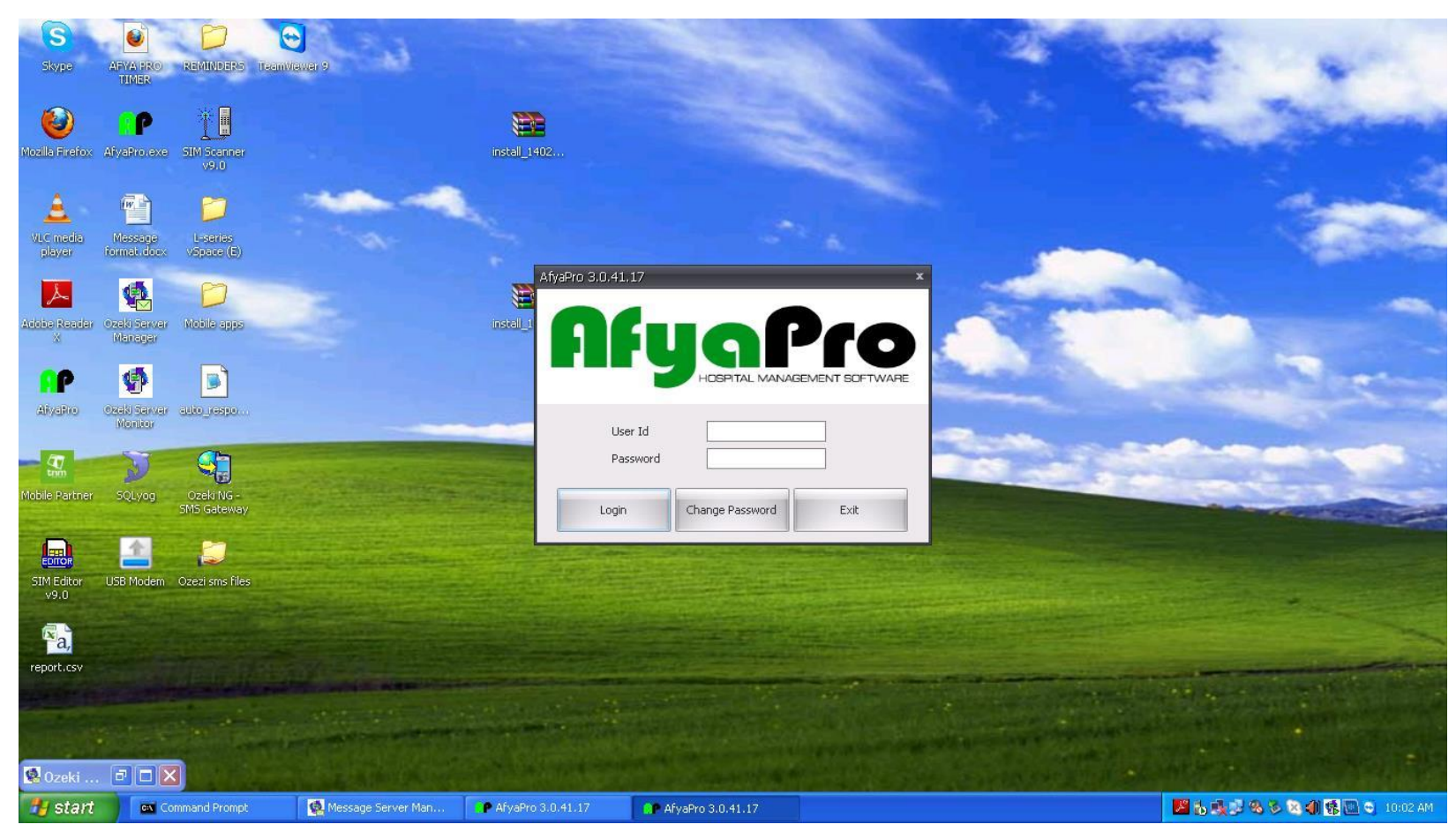

Figure 1. Login Window (above) and User Interface (below) of AfyaPro.

terpretation.

\section{QUALITATIVE COMPONENTS}

\section{KEY INFORMANT INTERVIEWS}

Thirteen semi-structured in-depth interviews were carried out with key stakeholders, selected on the basis of their role within the organisation and their involvement in the planning, delivery and use of the HIS over the period since its initial introduction (See Table 1). ${ }^{29}$ Respondents included four hospital managers, five health workers, three IT staff and a ward clerk. Interviews took place at the hospital, where the researcher also observed the use of the HIS system in practice. The main interviews were conducted over a four-month period, approximately 8 years after the system had been first rolled out. Follow-up interviews were undertaken iteratively to clarify findings as the study progressed. Each interview lasted an average 46 minutes and was documented by hand using annotated field notes, as well as audio recorded with the verbal consent of participants. Ethics approval was obtained from the National Health Sciences Research Committee at Malawi's Ministry of Health, and the University of Edinburgh. 


\section{DOCUMENT REVIEW}

The qualitative data sources also included meeting minutes and project documentation contained within the hospital's management archives and key reports describing elements of the wider context of the intervention, such as government policy changes or national health intervention programs. Documents were annotated and summarised as part of the research process.

\section{REVENUE DATA}

Insufficient data was available on the costs of the technology and associated change management interventions, to allow for a cost-benefit analysis. The quantitative analysis thus set out to describe patterns of revenue capture over time.

The observation period covered eight-years, encompassing three phases of implementation in September 2009 (out-patient department), July 2010 (inpatient department) and January 2012 (recruitment of ward data clerks).

Revenue data was obtained from the hospital's electronic and paper records systems and was available for the 44 months prior to initial rollout and 52 months thereafter. Total revenue was calculated by combining patient fees arising from out-patient consultations (available only from Jan 2009), and from in-patient services and dispensed drugs (available only from Jul 2010). Other sources, such as donations and grants, were excluded from the analysis.

\section{RESULTS}

The results are presented descriptively - by mapping changes in revenue against key events and stages over the project's timeline; qualitatively - through the analysis of respondents' recollections, observations and explanations; and statistically - by comparing pre- and post-implementation averages. Finally, we examine additional contextual influences that came to light during the study.

\section{HIS PROJECT TIMELINE AND IMPLEMENTATION PHASES}

Analysis of project documentation revealed that the HIS was first introduced at the hospital in September 2009, with modules for patient registration, billing, and diagnosis/ treatment introduced at the outpatient department. From July 2010, these modules were also introduced in the inpatient maternity, medical, surgical, private, TB/isolation and children's wards. (Additional modules in reproductive and child health and HIV/ART are still to be fully implemented and were not included in this study.) In January 2012 dedicated administrative staff, known as Ward Clerks, were introduced into the maternity, medical, surgical and paediatric wards as part of a wider quality improvement drive. Thereafter the Ward Clerks assumed the remit for data entry using the HIS and for preparing accurate bills for issuance by the accounts office. These phases are plotted against trends in the available revenue data in Figure 2.

\section{QUALITATIVE ANALYSIS}

Interviews explored key stakeholders' recollections, observations and explanations of how the HIS had influenced the efficiency of administrative processes, information for decision making and financial and patient outcomes at the hospital. Good-governance emerged as a dominant and lateral theme, as illustrated in the results below.

\section{TRACKING PATIENTS, PROCESSES AND COSTS}

Nine of the thirteen interviewees believed that implementing the HIS had reduced errors, improved accountability and increased revenue. They reported that, prior to the project, many patients presenting at the hospital were not recorded and were able to progress through the system without paying for consultation, admission or drugs. Electronic registration using the HIS had since enabled the hospital to more easily identify and track patients through the care process, recording the costs of services received within the inpatient and outpatient departments and through drug dispensing.
"With the manual system, a patient could see a clin- ician without paying, just because they are related or friends with the clinician. Even in the in-patient wards, the bills could easily be altered and some costs removed from the manual bill. That cannot happen with the electronic system. There are no more fake receipts with this system." - An IT staff member, 29 September.

\section{TRAINING AND PROCESS REORGANISATION}

HIS implementation was also associated with a range of non-technical changes. In the outpatient department this included recruitment of staff to register patients into the HIS before consultation, training accounts staff to provide computer-generated receipts, and requiring patients to have a printed receipt before drugs may be dispensed. This brought an end to the issuance of manual bills by individual staff. Patients now cannot pay at the cashier if they are not registered on the electronic system at reception and cannot receive drugs if they have not paid at the cashier. Pharmacy staff pointed out that while processes have been improved, they remain imperfect; for example, in the outpatient department it still depends on the discretion of the person dispensing to check that the patient has an electronic receipt. Nevertheless, they expressed optimism that implementation of the pharmacy modules would help to close this loop-hole.

\begin{abstract}
"[Drugs] prescribed cannot be paid for if there is no consultation fee payment. But currently without the dispensary software there is still a window of abuse where medicine can be dispensed and not paid for. Hopefully with the implementation of a pharmacy module then it will be even more difficult to abuse the system.” - A pharmacy staff member, 8 October.
\end{abstract}

\section{SOCIOCULTURAL INFLUENCES}

Interviews revealed that immediately after implementing the HIS in 2010 within the in-patient department, the system was managed by the same nurses and patient atten- 


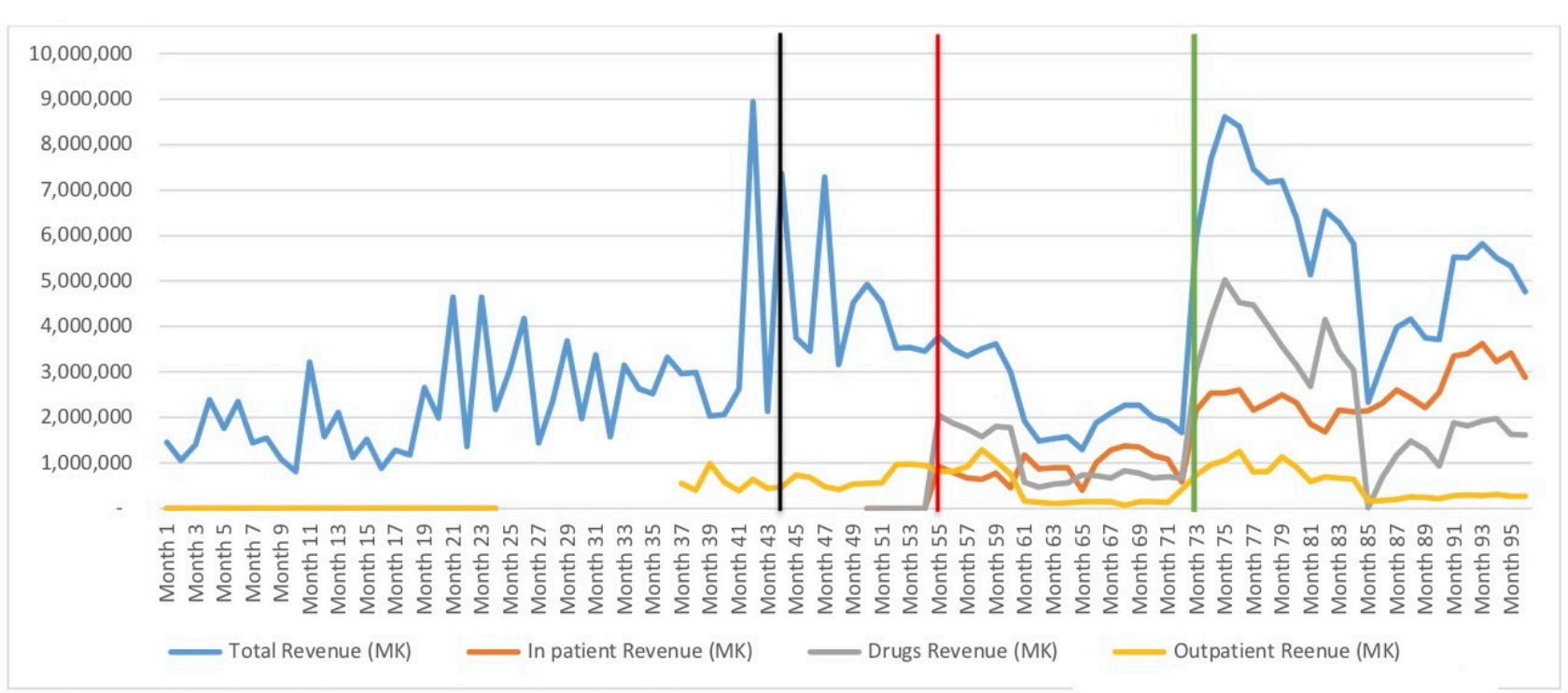

Black vertical line $=$ Subset of modules implemented in outpatient department Red vertical line $=$ Full set of inpatient and outpatient modules implemented Orange vertical line $=$ Introduction of ward clerks to undertake data capture

Figure 2. Trajectory of revenue data before and at different stages of HIS implementation.

Note: Line break indicates a gap in available OP documentation.

dants who had previously been responsible for data capture on paper, and billing was undertaken by the same accounts staff who received payment from clients. All of these staff were typically drawn from surrounding villages, creating social obligations upon them to alter patient files and bills for relatives and friends, as indicated in the first quote reproduced above. Before the introduction of Ward Clerks the opportunity to do this was equally available to these staff using the HIS as it had been with the paper-based systems. A manager describes how the introduction of Ward Clerks and other non-technical changes helped to improve this situation:

"A possible explanation for the increase in income could be the difficulty with altering electronic data as opposed to hand written receipts, separation of duties by having Ward Clerks, and closer monitoring of staff managing finances." - A hospital manager, 1 October.

The movement of paper files between various departments had also provided opportunities for records to be lost or adjusted:

"With the paper-based system, some tests or procedures would be lost or altered as the patient's paper file [went] from the ward to pharmacy to accounts and then back to the ward. Now the bill can be generated at the click of a button as the patient is being discharged." An accounts staff member, 30 September.

Another accounts staff member emphasised the practical advantages of having Ward Clerks using the HIS:

“This has been improved as, while there are still some departments that that do not have the electronic system and require collection of their paper records, bills can now be produced at one point [in the HIS], and only one person per department (the Ward Clerks) has the responsibility of getting the paper files from these de- partments and compiling the electronic bill.” - 24 Oc-
tober.

Now Ward Clerks compile the bills, the accounts staff enter the patient's number into the computer and the HIS generates an invoice, which cannot be altered. Further, the accounts staff only receive payments on the invoice due, and do not have access to compiling the bill in the HIS and cannot alter the invoice.

\section{WORKLOAD, DATA QUALITY AND ADMINISTRATIVE EFFICIENCIES}

Interviewees also drew attention to workload challenges affecting data quality prior to the introduction of Ward Clerks, with healthcare staff facing high patient volumes as well as requirements to complete multiple registers for the Ministry of Health. As a result, data entry was of poor quality and appropriate billing opportunities could be missed.

Devolving these tasks to Ward Clerks was thought to be helpful for easing these burdens, as well as for their governance value. Attention was also drawn to the workload of administrative staff and how the HIS was helping to improve this:

"It eased the work of the accounts. At a click they can
check how many consultations and whether they tally
with the money [collected] ... It is restricted to clerks
and accounts department staff to be able to go into the
billing system." - A clinician in the reproductive and
child health department, 24 November.

The Ward Clerks help to ensure that clinicians and nurses document all services to be billed and that these services are entered correctly onto the system, assisting the hospital to avoid loss of revenue as a result of incomplete documentation of services that have been provided or charge slips 
that are delayed or missing.

\section{INFORMING FINANCIAL OVERSIGHT}

Interviewees also highlighted the power of the data captured by the HIS to inform analytics for the purposes of audit, planning and cost containment:

\section{“... Other offices like the [Principal Hospital] Admin- istrator or the [Hospital] Accountant can view what is happening during the day through [the HIS]." - A clini- cian, paediatrics department, 26 November.}

This was corroborated by a key informant from the accounts department, who confirmed that, for the inpatient section:

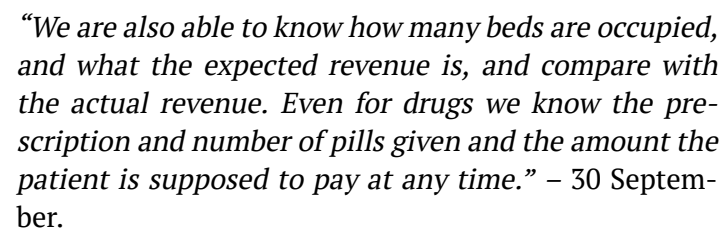

"We are also able to know how many beds are occupied, and what the expected revenue is, and compare with the actual revenue. Even for drugs we know the prescription and number of pills given and the amount the patient is supposed to pay at any time." - 30 September.

\section{MONITORING UNETHICAL FINANCIAL PRACTICES}

The advantages of the HIS for enabling management oversight and decision making also extended to the detection of dishonest practices. As early as 2012, managers had discovered that monitoring financial data using the HIS could uncover irregular patterns indicative of possible fraud.

"Previously, patients were conniving with staff to reduce the bill. Now there are checks and balances to counter that practice.” - An accounts staff member, $30^{\text {th }}$ September.

Some staff were even thought to have sabotaged the sys tem in the outpatient department in order to evade detection for taking informal payments:

\begin{abstract}
"We have an example of someone who would unplug the computer so that the accounts could authorise manual receipts because he benefitted from the manual system. This was at the cashier's office." - An IT staff member, 21 November.
\end{abstract}

\section{CHASING UNPAID BILLS}

Clients at the case study hospital often leave with unpaid bills and each year, the hospital loses an average MK9 million (US\$27,637) to bad debts. Since the HIS captures each client's full address, it also has potential to be used to follow-up debtors.

"We are not yet using AfyaPro to its full capacity because it is not yet generating the debtor statements by address so that the hospital can start collecting. Once this is in place then collections should increase even more! " - A hospital manager, 24 September.

\section{ANALYSIS OF REVENUE FROM PATIENT BILLING}

\section{DESCRIPTIVE DATA}

Data on total hospital income from patient fees was avail- able for the 44 months prior to the HIS being first implemented and 52 months after. Figure 2 shows the trends in raw revenue over time (total, inpatient, drugs, outpatient). Key HIS implementation stages are superimposed on the figures, for reference.

"Eyeballing" the quantitative data shown in Figure 2 is helpful for understanding how revenue patterns varied over time. We discuss this further in the section on contextual influences.

\section{REVENUE CAPTURE PRE- VS POST IMPLEMENTATION}

Although our case study was not intended as an economic evaluation, it is useful to examine revenue before and after system implementation, for comparison with stakeholders' perceptions.

In the pre-implementation period (month 0-43) mean monthly income from patient billing was MK2,528,185 [US\$ 7,764] (95\% confidence interval CI: MK2,037,970 [US\$6,258] - MK3,018,399 [US\$9,269]), compared with MK4,252,825 [US\$13,060] (95\% CI: MK3,703,046 [US\$11,371] MK4,802,605 [US\$14,748]) in the post-implementation period (months 37-95). This apparently large revenue increase (68\%) may explain the interview respondents' perception of the HIS' effects, however, a different outcome is observed after adjusting for inflation. This was achieved using the Malawi national Consumer Price Index (CPI) and adjusting backwards based on 2013 prices to calculate the expected revenue for each month. ${ }^{30}$ Inflation-adjusted monthly revenue in the pre-implementation period averaged MK4,986,795 [US\$15,314] (95\% CI: MK4,121,741 [US\$12,657] - MK 5,851,850 [US\$17,970]), compared with MK5,757,277 [US\$17,680] per month (95\% CI: MK5,044,025 [US\$15,489] - MK6,470,529 [US\$19,870]) in the post- implementation period. While this still represents a positive difference of approximately $15 \%$, it was not statistically significant (Mann-Whitney $\mathrm{U}=883, \mathrm{n} 1=52, \mathrm{n} 2=44, \mathrm{P}=.05$, two tailed). Factoring in the cost of employing the four Ward Clerks (MK355,982 [US\$1,093]), reduces the percentage increase in revenue still further, from $15 \%$ to $8 \%$.

\section{CONTEXTUAL INFLUENCES}

The wide fluctuation in total revenue levels shown in Figure 2 warranted further investigation and the documentary analysis suggested several contextual factors that may have been influential.

In 2007 the Ministry of Health began to reimburse hospitals for serving pregnant women and young children, leading to a marked increase in attendance, which is consistent with the revenue increase seen in Figure 2 from month 41. In parallel with the implementation of the HIS in 2009, the government also implemented a major anti-malaria programme, which subsequently reduced malaria admissions, coinciding with the dip in income between months 59 and 73 in Figure 2. While firm attribution is impossible without further data, it is conceivable that the above two influences may have partially disguised the true effect of the HIS.

A more obvious influence, at the organisational level, was the introduction of specialist Ward Clerks in Jan 2012. This marked a key turning point for the HIS project, since 
it moved responsibility for data capture and entry from operational staff to dedicated administrators. The clear increase in patient revenue shown in month 75 coincides with these staff appointments and is consistent with the qualitative accounts of our interview respondents, although longer term data was not available to determine whether this effect was sustained.

A secondary observation which emerged during our analysis relates to the pattern of inflationary pressures in Malawi, which affects the degree of confidence that can be placed on adjusted revenue data. We used a standard method of correction, ${ }^{31}$ which is well suited to health systems with predictable economic trajectories and regulated unit pricing, such as the UK. However our examination of Consumer Price Index figures in Malawi revealed that, during the lifetime of the HIS implementation project, inflation in fluctuated widely, ranging from a record low of $6.30 \%$ in December 2010 to a record high of 37.90\% in February 2013. 32 Moreover, an examination of hospital documentation revealed inconsistent increases in the charges levied for different types of product or service, which did not appear to be correlated with CPI. This substantial variability suggests that more precise, dynamic adjustments may be necessary in such settings. These observations also provide further contextual information for the case study.

\section{DISCUSSION}

The results of this study reveal a rich picture of sociotechnical dynamics and complex influences in a long-term HIS implementation project taking place in a lower income country. The qualitative data show how the pathway through which the system influenced hospital revenue differed from that envisaged by the project's original commissioners, with a somewhat mechanistic view of efficiency gains giving way to a story of behavioural and cultural change, mediated by new staff roles. This revealed an unexpected landscape of unethical or unauthorised billing practices, which the HIS, in combination with Ward Clerks, helped to prevent. While qualitative perceptions of improvement were not matched by evidence of revenue changes, converging the data sources provides support for this interpretation. Documentary analysis undertaken for the study also sheds light on some of the difficulties involved in trying to measure the effects of information systems embedded in complex and changing organisational, political and economic contexts.

\section{RELEVANCE TO LITERATURE ON THE ROLE OF HIS IN HOSPITAL FINANCE AND BILLING}

The non-significant increase in mean monthly revenue after HIS implementation mirrors findings from a similar study using the same HIS at three hospitals in Tanzania. 33 However for the reasons noted, these changes are hard to interpret, given the influence of extraneous factors, data variability and uncertainties over inflation adjustment.

Many studies have reported unchanged, or barely changed, financial outcomes following HIS implementation, ${ }^{34,35}$ or even a loss of revenue, particularly in the early years of HIS adoption. ${ }^{36}$ Like our research, it is common for these to examine changes over time in order to under- stand both detrimental effects during the start-up phase and longer-term benefits once systems have embedded. 37 Loss of revenue in the initial phases of HIS implementation is associated with change management issues such as disruptions in access to patient data, effects on staff productivity ${ }^{38}$; costs of electricity and internet services, ${ }^{39}$ and non IT costs such as the need for new personnel. ${ }^{40}$ Increases in Returns on Investment may take time, for these reasons, but may eventually come about through efficiency gains that increase patient throughput and charge capture and billing, as well as quality improvements. ${ }^{41-44}$ In contrast to our study, the vast majority of this research has been conducted in high income countries, focuses primarily on efficiency measures and often fails to take longer term effects into account. While there are some similarities to the data reported here, their applicability to low income country settings such as rural Malawi, is unclear.

Within the quality improvement literature the prevailing narrative surrounding HIS is that they will decrease costs by improving the timeliness, efficiency, appropriateness and safety of healthcare, due to more accurate and complete patient data and the ability to deliver information when and where it is most needed. ${ }^{8}$ Embedded within this is the realisation that such systems can facilitate patient billing, as demonstrated in studies showing fewer errors, more effective charge capture, and improved cash flow. 10,41,44-46 Echoing this observation, several interviewees at the hospital reported a general improvement in the capture of data items pertaining to billable services such as patient consulting, treatments and drugs, which they attributed to the use of the system. Interviewees described how, prior to the introduction of the system, many patients had been able to skip registration at entry or payment for drugs, with the result that their care encounter was not documented, no revenue was gathered during their visit, and they could not be followed up. Inpatient revenue was also lost through incomplete manual bills, which failed to document all of the care or drugs received. Implementation of the HIS closed some of these loopholes by requiring that every patient be registered on the system before they could receive a physician consultation and pay for a screening consultation before receiving a prescription, although patients can still, if they choose, exit the hospital without purchasing the drugs they have been prescribed.

\section{GOVERNANCE AS THE MEDIATOR OF IMPROVEMENT}

Converging the hospital's financial records with the documentary analysis and interviews revealed what is perhaps the most salient observation of this study, in terms of its implications for eHealth adoption in lower income countries. This is that the main increase in revenue did not materialise until after the introduction of Ward Clerks, whose remit was to ensure that all patients and procedures were recorded, and patients billed appropriately using the HIS. This significantly changed the role of nurses, patient attendants and accounts staff, who had previously been responsible for these activities. Although users and managers saw the HIS as contributing to revenue improvements at the hospital, they explained this largely in terms of staff behaviour and culture, rather than as a simple effect of the tech- 
nology on process efficiency. The sociotechnical system implemented here consisted of, as one manager put it, electronic as opposed to hand written receipts, separation of duties, and closer monitoring of staff managing finances.

Most interviewees drew attention to unethical or unauthorised practices by staff members, such as documentation being altered, or billing stages by-passed. This included favour-giving to friends and relatives as well as employees receiving fees from patients without recording them. Immediately after the introduction of the HIS, the same staff continued to be responsible for data capture and billing processes, on the assumption that the system itself would lead to improvements. However, they were simply able to replicate the workarounds previously used with the paperbased system. After the recruitment of the Ward Clerks, many of these loopholes were closed and greater transparency and accountability afforded by the system, and the people managing it, led to disciplinary actions and noticeably reduced these practices. It is important to note that these changes were part of a wider set of financial management measures instituted by the hospital, such as new training and accounting practices. However, it is noteworthy that issues relating to billing workarounds and lack of transparency dominated interviewees' accounts of the governance-enabling role of the HIS.

Illicit practices such as those reported here are a persistent problem in lower income countries. 47,48 Since health services in these countries are typically free at public facilities, there has been little research on the use of ICT to address these issues, ${ }^{20}$ a gap which this study aims to help fill. Similar findings to our study have been reported from Kenya, which managed to combat staff theft of user fees through a governance intervention involving networked electronic cash registers, coupled with more attentive management and the separation of billing and fee collection activities. This improved accountability through more detailed recording and analysis of activities, including comparisons of actual to expected revenue, and enabled greater transparency through issuing printed receipts to patients. Implementation was associated with a 47 percent increase in patient fee revenue within three months, with no effect on service utilisation, and a 400\% increase within three years, although these impressive results require replication. 48

\section{SOCIOTECHNICAL SYSTEMS}

“Technologies mirror our societies by reproducing and embodying the complex interplay of professional, technical, economic and political factors." 49 While the original brief for our study was to evaluate the cost-benefit of the HIS implementation project, our interdisciplinary team quickly recognised the advantages of approaching it as a sociotechnical study, as more was learned about the history of the project and the contextual factors surrounding it, and a priori assumptions about users' work practices, incentives and the role of the system were challenged. The absence of reliable data on the costs of implementation, such as hardware, software, training, and maintenance, also played a role in this decision.

Sociologists of technology recognise the co-dependency of information systems and their users and settings within sociotechnical systems, where human and organisational factors influence or 'shape' the technology whilst introducing technology may shape professional roles and work practices. ${ }^{49,50}$ Such authors therefore argue that information systems projects should be approached as a process of organisational development, taking account of the social context and consequences of implementation, 51 rather than focusing on the technology alone. In the case of the setting studied here, the elements of the sociotechnical system included not only the technology that was rolled out but also efforts to train cashiers and reception staff in the outpatient department and inpatient nurses and patient attendants, and the recruitment of Ward Clerks to replace the billing roles of the inpatient department nurses, patient attendants and accounts staff.

In a similar way, the introduction of patient records in the US at the beginning of the twentieth century necessitated changes in hospital architecture and the emergence of the new profession of medical record managers. ${ }^{50,51} \mathrm{Re}-$ searchers in the field of eHealth also recognise that introducing such innovations can disrupt existing work processes and often require additional change management and service redesign efforts, which make it hard to disentangle the effects of the technology from the human and organisational processes that surround it. ${ }^{52,53}$ Our findings illustrate the importance of continuing to analyse workforce needs in the months after HIS are rolled out rather than, as in this case, letting years pass before recognising that new staff may be required to realise the benefits of technology use.

\section{EVALUATION AND COMPLEXITY}

Introducing new health information systems can be complex and demonstrating their impacts without controlled trials represents a challenge for evaluation. ${ }^{54}$ For these reasons, evaluations focused on clinical and cost indicators can have limited generalisability and sociotechnical studies may be more useful for uncovering unanticipated influences and effects. ${ }^{25,54}$ Undertaking such projects in low income country settings adds an additional layer of complexity, leading some researchers to argue that quantifying hard outcomes may be less important than understanding ICT as an enabler of socio-economic development. ${ }^{55,56}$ By converging quantitative data from the hospital's finance records with qualitative analysis of interviews and documentation, we were able to reveal a rich picture of the macro-environmental factors influencing revenue fluctuations, as well as examining how the HIS project influenced billing practices and the importance of role separation as a mediator of governance.

\section{STUDY LIMITATIONS}

Given the many confounding influences described above, it is impossible to definitively attribute improvements in hospital revenue to implementation of the HIS. Nevertheless, the convergence of qualitative and quantitative data in our study lends support to this interpretation, whilst emphasising that the ability of the system to affect financial gov- 
ernance was contingent upon its appropriate use. We acknowledge the small number of key informants interviewed in-depth. As with most case studies using qualitative methods, the aim was not to achieve statistical generalisability, but rather analytical generalisability. 28 The interviews were retrospective, and thus limited by hindsight, although triangulation with historical financial and documentary data helped to validate the participants' recollections and reflections. The absence of data on the actual costs of implementation (hardware, software, training, maintenance) and detailed unit prices, alongside erratic inflation rates, further illustrate the challenges involved in evaluating the cost-effectiveness of eHealth interventions in developing countries and the need for mixed methods. ${ }^{57,58}$ While most interview participants described the importance of the Ward Clerks in effectively deploying the system, the marked increase in billing revenue immediately after their recruitment may be coincidental and the effect reduced the following year. It is possible that as they became more integrated within local teams, increased social pressure reduced their motivation to report objectively. As junior clerical staff, mostly recruited from the surrounding villages, these pressures may have been further exacerbated. As only two years of data were available, however, it was not possible to explore these longer-term effects.

\section{IMPLICATIONS FOR PRACTICE}

Weak financial governance represents a major barrier to the delivery of equitable, effective and sustainable healthcare worldwide. 2,3,59 Although the problem is recognised by most global development agencies, it remains a politically sensitive issue and is often lost in the commitment to raise funds and expand services ${ }^{4}$ whilst regulation and enforcement are often ineffective. ${ }^{48,60}$ These problems are exacerbated by institutional factors, such as inconsistent salary payments, and organisational norms that encourage tipping, informal payments, minor theft or favour-giving, coupled with a lack of monitoring and oversight, which enables such practices to flourish unhindered. 16,47,61 Our study draws attention to the capacity of HIS to ameliorate these problems by reducing opportunities for billing workarounds, improving the recording of chargeable items and increasing accountability. It also reinforces the need to approach such projects with a clear view of the environmental, organisational, and sociocultural contexts affecting them. Leaders considering such systems need to be aware of the need to blend technological approaches with workflow redesign or new personnel in order to overcome entrenched norms or conflicting roles. ${ }^{62}$ It should also be recognised that not all diversions from correct billing are inherently unethical; for example, overlooking charges for a patient who is in great need but is unable pay for treatment may align with a health worker's moral motive even if not within their remit as an employee. Likewise, the strong influence of social obligations should not be underestimated. In a rural area it is likely that anyone who has advanced in their education and has a good job is known by many people in the surrounding villages and is expected to assume the role of a benefactor, placing them under considerable pressure to bend the rules. Separating the roles of health- care practitioners and administrators may help to address these challenges. Improving accountability, transparency, monitoring and enforcement has been identified as a "grand challenge" for global health governance 63 and the potential of HIS to improve health intelligence and encourage new norms has been recognised as part of wider strategies that include awareness raising and education. ${ }^{21,64}$ Where these factors are not taken into account, the introduction of such technologies may merely perpetuate poor governance practices or even increase them. 65

\section{CONCLUSIONS}

Introducing digital health information systems may strengthen financial governance in lower income countries through improved recording of patients and procedures, greater fee recovery and increased professional accountability. However, as this study illustrates, realising such benefits is not straightforward and demands changed practices and new roles in order to ensure that systems are used effectively. It also demonstrates the importance of taking contextual influences into account when attempting to explain impacts, and the benefits of evaluating such projects as complex sociotechnical systems. Additional research is required to establish the impacts of HIS on financial governance, taking account of the many costs involved in their set-up, roll-out and on-going sustainability. ${ }^{66}$ Lack of complete and reliable revenue data, inconsistent pricing and unstable inflationary pressures are likely to complicate such research in these settings and call for innovative methodologies. Although we are unable to draw firm conclusions about the impacts of the HIS on revenue capture at the case study hospital, the study has offered important insights into the importance of managing change, understanding context and work culture, and anticipating challenges for evaluation. It also feeds the growing literature on digital goodgovernance interventions for lower income country health systems. ${ }^{20}$ Mindful of the complexities underpinning both financial governance and eHealth implementation, we recommend that further interdisciplinary research is carried out to improve understanding of their mutual influence and impacts.

Acknowledgements: We thank the management and staff at the hospital for participating in the study, particularly Agness Nyanda the then Hospital Accountant and current Principal Hospital Administrator, and Dr David Morton the then Deputy Medical Director, for enabling access to the relevant financial and institutional data. Thanks also to Andrew Stoddart, at the University of Edinburgh's Health Services Research Unit, for statistical advice, and Judith Schoot Uiterkamp, Miep Lenoir and Ramon Salat at IICD for comments on an earlier draft.

Funding: The research was funded by the International Institute for Communication and Development (IICD), a Dutch non-profit foundation focused on ICT for development.

Authorship contributions: The project forms part of PK's $\mathrm{PhD}$ research, supervised by $\mathrm{CP}$ and LG. PK designed the 
study, collected and analysed the data and first-drafted the manuscript. CP co-designed the study, co-analysed the qualitative data and co-wrote the manuscript. LG contributed to the study design and analysis and commented on the manuscript. All authors read and approved the final manuscript.

Conflicts of interest: The authors completed the Unified Competing Interest form atwww.icmje.org/coi_disclosure.pdf (available upon request from the corresponding author), and declare no conflicts of interest.

\section{Correspondence to:}

Claudia Pagliari BSc PhD FRCPE

Director of Global eHealth

Usher Institute

University of Edinburgh

Old Medical School

Teviot Place

Edinburgh

UK

Claudia.pagliari@ed.ac.uk 


\section{REFERENCES}

1. Black AD, Car J, Pagliari C, et al. The impact of eHealth on the quality and safety of health care: A systematic overview. Djulbegovic B, ed. PLoS Med. 2011;8(1):e1000387. doi:10.1371/journal.pmed.10003 $\underline{87}$

2. Mugo J. Improving governance in healthcare systems in Africa [Internet]. Consultancy Africa Intelligence. 2013. http://www.polity.org.za/article/i mproving-governance-in-healthcare-systems-in-afric a-2013-02-26. Accessed January 2, 2020.

3. Joshi DK, Hughes BB, Sisk TD. Improving Governance for the Post-2015 Sustainable Development Goals: Scenario Forecasting the Next 50 years. World Dev. 2015;70:286-302. doi:10.1016/j.worl ddev.2015.01.013

4. Lewis M. Tackling Healthcare Corruption and Governance Woes in Developing Countries [Internet]. Governance and Corruption in Public Health Care Systems. Washington, DC; 2006. https://www.cgdev.o rg/sites/default/files/7732_file_GovernanceCorruptio n.pdf. Accessed January 2, 2020.

5. McReavy DJ, Toth L, Tremonti C, Yoder C. The CFO's role in implementing EHR systems. Healthc Financ Manage. 2009;63(6):72-76. http://www.ncbi.nl m.nih.gov//19526822.

6. Giniat EJ. Using business intelligence for competitive advantage. Healthc Financ Manage. 2011;65(9):142-16. http://www.ncbi.nlm.nih.gov//219 $\underline{23053}$.

7. Agrawal A. Return on investment analysis for a computer-based patient record in the outpatient clinic setting. J Assoc Acad Minor Phys.

2002;13(3):61-65. http://www.ncbi.nlm.nih.gov//1236 2561.

8. Hillestad R, Bigelow J, Bower A, et al. Can electronic medical record systems transform health care? Potential health benefits, savings, and costs. Health Aff (Millwood). 2005;24(5):1103-1117. doi:10.1 $\underline{377 / \text { hlthaff.24.5.1103 }}$

9. Wang SI, Middleton B, Prosser LA, et al. A costbenefit analysis of electronic medical records in primary care. Am J Med. 2003;114(5):397-403. doi:1 $\underline{0.1016 / \mathrm{s} 0002-9343(03) 00057-3}$

10. Silow-Carroll S, Edwards JN, Rodin D. Using electronic health records to improve quality and efficiency: The experiences of leading hospitals. Commonwealth Fund. 2012;(17):1-40. http://www.nc bi.nlm.nih.gov//22826903.
11. Pejic-Bach M. Invited Paper: Profiling Intelligent Systems Applications in Fraud Detection and Prevention: Survey of Research Articles. In: 2010 International Conference on Intelligent Systems, Modelling and Simulation. IEEE; 2010:80-85. doi:10.1 $\underline{109 / \text { isms.2010.26 }}$

12. Ngai EWT, Hu Y, Wong YH, Chen Y, Sun X. The application of data mining techniques in financial fraud detection: A classification framework and an academic review of literature. Decis Support Syst. 2011;50(3):559-569. doi:10.1016/j.dss.2010.08.006

13. Joudaki H, Rashidian A, Minaei-Bidgoli B, et al. Improving Fraud and Abuse Detection in General Physician Claims: A Data Mining Study. Int J Health Policy Manag. 2015;5(3):165-172. doi:10.15171/ijhp $\underline{\mathrm{m} .2015 .196}$

14. Aral KD, Güvenir HA, Sabuncuoğlu İ, Akar AR. A prescription fraud detection model. Computer Methods Programs Biomed. 2012;106(1):37-46. doi:1 0.1016/i.cmpb.2011.09.003

15. Hussmann K. Addressing corruption in the health sector: Securing equitable access to health care for everyone [Internet]. https://www.cmi.no/publication s/3934-addressing-corruption-in-the-health-sector. Published 2011. Accessed January 2, 2020.

16. Muula AS, Maseko FC. How are health professionals earning their living in Malawi? BMC Health Serv Res. 2006;6(1):97. doi:10.1186/1472-696 3-6-97

17. United Nations. Goal 16: Promote just, peaceful and inclusive societies [Internet]. Sustainable Development Goals. 2016. http://www.un.org/sustain abledevelopment/peace-justice/.

18. Scheffler RM, Mahoney CB, Fulton BD, Dal Poz MR, Preker AS. Estimates of health care professional shortages in Sub-Saharan Africa by 2015. Health Aff (Millwood). 2009;28(5):w849-w862. doi:10.1377/hltha ff.28.5.w849

19. Blaya JA, Fraser HSF, Holt B. E-Health technologies show promise in developing countries. Health Aff (Millwood). 2010;29(2):244-251. doi:10.13 77/hlthaff.2009.0894

20. Holeman I, Cookson TP, Pagliari C. Digital technology for health sector governance in low and middle income countries: A scoping review. J Glob Health. 2016;6(2):020408. doi:10.7189/jogh.06.02040 $\underline{8}$ 
21. Lewis M. Governance and corruption in public health care systems [Internet]. Governance and Corruption in Public Health Care Systems. Washington DC; 2006. (CGD Working Paper). Report No.: 78. 2006. doi:10.2139/ssrn.984046

22. Driessen J, Cioffi M, Alide N, et al. Modeling return on investment for an electronic medical record system in Lilongwe, Malawi. J Am Med Inform Assoc. 2013;20(4):743-748. doi:10.1136/amiajnl-2012-00124 $\underline{2}$

23. Piette J, Lun K, Moura L, et al. Impacts of e-health on the outcomes of care in low- and middle-income countries: Where do we go from here? Bull World Health Org. 2012;90(5):365-372. doi:10.2471/blt.11.0 $\underline{99069}$

24. Ammenwerth E, Gräber S, Herrmann G, Bürkle T, König J. Evaluation of health information systems: Problems and challenges. International Journal of Medical Informatics. 2003;71(2-3):125-135. doi:10.10 16/S1386-5056(03)00131-X

25. Cresswell KM, Sheikh A. Undertaking sociotechnical evaluations of health information technologies. Inform Prim Care. 2014;21(2):78-83. do i:10.14236/ihi.v21i2.54

26. Organization WH. Developing Health Management Information Systems: A Practical Guide for Developing Countries. Geneva, Switzerland; 2004. https://iris.wpro.who.int/handle/10665.1/5498.

27. Moens N, Broerse J. Innovating in sectoral governance and development with ICT:

Conceptualising the ICT Roundtable process. Systemics, Cybernetics and Informatics [Internet]. 2006;4(6):33-40. http://www.iiisci.org/Journal/CV\$/sc i/pdfs/p738537.pdf.

28. Yin RK. Case study research: Design and methods. In: Knight V, Habib S, Chilton CM, Dickens G, eds. Vol 5. 4th ed. Applied Social Research Methods Series. London: SAGE Publications, Inc; 2009:1-171.

29. Marshall M. The key informant technique. Fam Pract. 1996;13(1):92-97. doi:10.1093/fampra/13.1.92

30. Kumaranayake L. The real and the nominal? Making inflationary adjustments to cost and other economic data. Health Policy and Planning. 2000;15(2):230-234. doi:10.1093/heapol/15.2.230

31. Thompson G. Statistical Literacy Guide: How to Adjust for Inflation [Internet].; 2009. http://www.parl iament.uk/briefing-papers/sn04962.pdf. Accessed January 2, 2020.
32. Economics T. Malawi Inflation Rate [Internet].; 2015. https://tradingeconomics.com/malawi/inflatio n-cpi. Accessed January 2, 2020

33. Leon BK. Evaluation of the computer assisted hospital data management system in Tanga. Deutsche Gesellschaft für Internationale Zusammenarbeit. 2012. https://docplayer.net/8679797-Evaluation-of-th e-computer-assisted-hospital-data-management-syst em-in-tanga.html. Accessed January 2, 2020.

34. Lim MC, Patel RP, Lee VS, Weeks PD, Barber MK, Watnik MR. The long-term financial and clinical impact of an electronic health record on an academic ophthalmology practice. J Ophthalmol. 2015;2015:329819. doi:10.1155/2015/329819

35. Chiang MF, Read-Brown S, Tu DC, Choi D, Sanders DS, Hwang TS, et al. Evaluation of electronic health record implementation in ophthalmology at an academic medical center (an American Ophthalmological Society thesis). Transactions of the American Ophthalmological Society. 2013;111:70-92. https://www.ncbi.nlm.nih.gov//24167326.

36. Menachemi N, Powers TL, Brooks RG. Physician and practice characteristics associated with longitudinal increases in electronic health records adoption. Journal of healthcare management / American College of Healthcare Executives. 2011;56(3):183-197; discussion 197-8. doi:10.1097/00 115514-201105000-00007

37. Adler-Milstein J, Green CE, Bates DW. A Survey analysis suggests that electronic health records will yield revenue gains for some practices and losses for many. Health Aff (Millwood). 2013;32(3):562-570. do i:10.1377/hlthaff.2012.0306

38. Police RL, Foster T, Wong KS. Adoption and use of health information technology in physician practice organisations : Systematic review. Inform Prim Care. 2010;18(4):245-258. doi:10.14236/ihi.v18i4.780

39. Gleason RP, Farish-Hunt H. How to choose or change an electronic health record system. J Nurse Pract. 2014;10(10):835-839. doi:10.1016/i.nurpra.201 $\underline{4.06 .010}$

40. Ko M, Osei-Bryson K-M. Reexamining the impact of information technology investment on productivity using regression tree and multivariate adaptive regression splines (MARS). Information Technology and Management. 2008;9(4):285-299. do i:10.1007/s10799-008-0036-z

41. Bardhan IR, Thouin MF. Health information technology and its impact on the quality and cost of healthcare delivery. Decision Support Systems. 2013;55(2):438-449. doi:10.1016/j.dss.2012.10.003 
42. Choi JS, Lee WB, Rhee P-L. Cost-benefit analysis of electronic medical record system at a tertiary care hospital. Healthc Inform Res. 2013;19(3):205-214. do $\mathrm{i}: 10.4258 /$ hir.2013.19.3.205

43. Abraham C, Junglas I. From cacophony to harmony: A case study about the IS implementation process as an opportunity for organizational transformation at Sentara Healthcare. J Strateg Inf Syst. 2011;20(2):177-197. doi:10.1016/i.jsis.2011.03.0 $\underline{05}$

44. Smith AL, Bradley RV, Bichescu BC, Tremblay MC, Bradleyt RV, Bichescu BC, et al. IT governance characteristics, electronic medical records sophistication, and financial performance in U.S. hospitals: An empirical investigation. Decision Sciences. 2013;44(3):483-516. doi:10.1111/deci.12019

45. Sidorov J. It ain't necessarily so: The electronic health record and the unlikely prospect of reducing health care costs. Health Aff (Millwood). 2006;25(4):1079-1085. doi:10.1377/hlthaff.25.4.1079

46. Menachemi N. Benefits and drawbacks of electronic health record systems. Risk Manag Healthc Policy. May 2011:47-55. doi:10.2147/rmhp.s12985

47. Lewis M. Informal payments and the financing of health care in developing and transition countries. Health Aff (Millwood). 2007;26(4):984-997. doi:10.137 7/hlthaff.26.4.984

48. Vian T. Review of corruption in the health sector: Theory, methods and interventions. Health Policy Plan. 2007;23(2):83-94. doi:10.1093/heapol/czm048

49. Bijker WE, Law J. Shaping Technology/Building Society: Studies in Sociotechnical Change. MIT press; 1992.

50. Williams R, Edge D. The social shaping of technology. Res Policy. 1996;25(6):865-899. doi:10.10 16/0048-7333(96)00885-2

51. Berg M. Patient care information systems and health care work: A sociotechnical approach. Int J Med Inform. 1999;55(2):87-101. doi:10.1016/s1386-5 056(99)00011-8

52. Berg M. Implementing information systems in health care organizations: Myths and challenges. Int J Med Inform. 2001;64(2-3):143-156. doi:10.1016/s138 6-5056(01)00200-3

53. Pagliari C. mHealth, Telehealth and the Digital Soceity: Where does the "value" lie? [Internet]. Health \& Medicine. 2012. http://www.webcitation.or g/6ccGLKFOE.
54. McLean S, Sheikh A, Cresswell K, et al. The impact of telehealthcare on the quality and safety of care: A systematic overview. Lovis C, ed. PLOS ONE. 2013;8(8):e71238. doi:10.1371/journal.pone.0071238

55. Harris AD, McGregor JC, Perencevich EN, et al. The use and interpretation of quasi-experimental studies in medical informatics. Journal of the American Medical Informatics Association. 2006;13(1):16-23. doi:10.1197/jamia.m1749

56. Gomez R, Pather S. ICT evaluation: Are we asking the right questions? The Electronic Journal of Information Systems in Developing Countries. 2012;50(1):1-14. doi:10.1002/j.1681-4835.2012.tb003 $\underline{55 . \mathrm{X}}$

57. Venkatesh V, Brown SA, Bala H. Bridging the qualitative-quantitative divide: Guidelines for conducting mixed methods research in information systems. Manage Inf Syst Q. 2013;37(1):21-54. doi:1 $\underline{0.25300 / \mathrm{misq} / 2013 / 37.1 .02}$

58. Creswell JW. A Concise Introduction to Mixed Methods Research. 1st ed. London: SAGE Publications, Inc; 2015.

59. Dasandi N, Hudson D, Pegram T. Governance and institutions. In: Waage J, Yap C, eds. Thinking Beyond Sectors for Sustainable Development. London: Ubiquity Press; 2015:63-76. doi:10.5334/bao.h

60. Swanson R, Atun R, Best A, et al. Strengthening health systems in low-income countries by enhancing organizational capacities and improving institutions. Global Health. 2015;11(1):5. doi:10.1186/s12992-01 5-0090-3

61. Fritzen SA. Strategic management of the health workforce in developing countries: What have we learned? Hum Resour Health. 2007;5(4). doi:10.1186/ 1478-4491-5-4

62. Bossen C, Foss M. The collaborative work of hospital porters: Accountability, visibility and configurations of work. In: Proceedings of the 19th ACM Conference on Computer-Supported Cooperative Work \& Social Computing - CSCW'16. ACM Press; 2016:965-979. doi:10.1145/2818048.2820 $\underline{002}$

63. Gostin LO, Mok EA. Grand challenges in global health governance. Br Med Bull. 2009;90(1):7-18. do i:10.1093/bmb/ldp014

64. Stansfield S. Structuring information and incentives to improve health. Bull World Health Organ. 2005;83(8):562. http://www.ncbi.nlm.nih.gov/ pmc/articles/PMC2626310/. 
65. Bowman S. Impact of Electronic Health Record Systems on Information Integrity: Quality and Safety Implications. Perspect Health Inf Manag.

2013;1;10(Fall):1c-1c:1-1. http://www.ncbi.nlm.nih.g ov/pmc/articles/PMC3797550/.
66. Lewis T, Synowiec C, Lagomarsino G, Schweitzer J. E-health in low- and middle-income countries: Findings from the Center for Health Market Innovations. Bull World Health Organ. 2012;90(5):332-340. doi:10.2471/blt.11.099820 